\title{
Da visão do gestor a realidade do professor: uma análise da Formação Continuada referente as Novas Tecnologias em escolas estaduais de Minas Gerais
}

\author{
Karina Letícia Júlio Pinto ${ }^{1}$, Júlia Marques Carvalho da Silva ${ }^{2}$ \\ ${ }^{1}$ Instituto Federal do Rio Grande do Sul- IFRS - Porto Alegre - RS - Brasil \\ ${ }^{2}$ Instituto Federal do Rio Grande do Sul- IFRS - Bento Gonçalves - RS - Brasil \\ karina.leticia2lehotmail.com, julia.silva@bento.ifrs.edu.br
}

\begin{abstract}
This article has tried to identify if the vision of the manager for continued training for new technologies contemplates the reality of professor. For this reason we held an interview with the manager of the pedagogical NTE regional and a research survey, with 219 teachers of state schools in Minas Gerais. It was noticed that we need dialog between teachers and staff policy of the school, for the construction of projects, in partnership with the regional NTE can be means of continued training of teachers.
\end{abstract}

Resumo. Este artigo procurou identificar se a visão do gestor referente a formação continuada para as novas tecnologias contempla a realidade do professor. Para isso, foi realizada uma entrevista com o gestor pedagógico do NTE regional e uma pesquisa survey, com 219 professores de escolas estaduais de Minas Gerais. Percebeu-se que é preciso o diálogo entre os professores e a equipe diretiva da escola, para a construção de projetos, que em parceria com o NTE regional possam ser meios de formação continuada dos docentes.

\section{Introdução}

As novas tecnologias "transformam espetacularmente não só nossas maneiras de comunicar, mas também de trabalhar, de decidir, de pensar" (Perrenoud, 2000, p. 124) e a escola não pode negar aos alunos a sociedade atual e os novos meios midiáticos de informação e comunicação. Os professores são os principais agentes das mudanças no meio educativo, principalmente na formação de sujeitos críticos e ativos na sociedade. Segundo o Estudo exploratório sobre o professor brasileiro com base nos resultados do Censo Escolar da Educação Básica 2007 (MEC), aproximadamente 61,7\% possuem a formação inicial (licenciatura), no entanto quanto a formação continuada não é apresentado dados suficientes para mapear a situação dos professores brasileiros.

A preocupação em equipar as escolas através do Programa Nacional de Tecnologia Educacional (ProInfo) proporcionou a introdução das Tecnologias da Informação e Comunicação (TIC) em todo o sistema de ensino do Brasil, no entanto é ilusório pensar que somente obtendo as ferramentas (computadores, tablet, lousa digital...) haverá na escola uma mudança quanto as práticas tradicionais e a efetiva utilização desses recursos. Pesquisa realizada em escolas públicas brasileiras referentes a incorporação das novas tecnologias, revelam que "a transformação escolar está acontecendo com maior frequência em situações nas quais diretores e comunidade escolar (funcionários, professores, alunos, pais e comunidade) se envolvem diretamente no trabalho realizado em seu interior" (Almeida e Menezes, 2004, p. 1). Nesse sentido, os 
professores como parceiros permitem construir juntos aos "especialistas em tecnologia, abordagens inovadoras de aprendizagens. Novos tempos, novas tecnologias e nova cultura com a presença dos educadores" (Martia, 2008, p. 1). Portanto, no "âmbito pedagógico nada encerra toda a verdade, tudo comporta e exige continua atualização" (MEC/CNE, 2001, p. 7).

Pesquisadores do Brasil (Brito, Duarte e Baía, 2004; Real e Tavares 2015) e de outros países como Portugal (Fernandes, 2006; Lisbôa et al., 2009) realizam estudos que apontam a falta de formação inicial e continuada do professor, um denominador comum que é entrave para a utilização das Tecnologias da Informação e Comunicação- TIC no cotidiano das práticas escolares. Com base neste cenário, definiu-se o seguinte problema: A visão do gestor frente as políticas de formação continuada envolvendo as novas tecnologias reflete a realidade do professor?

\section{Metodologia}

Inicialmente foi realizada uma entrevista com o Núcleo de Tecnologia Educacional- NTE que é responsável as escolas da regional pesquisada, buscando identificar as políticas de formação continuada adotada. Em seguida, foi realizada a pesquisa survey, por meio de um questionário com a participação de 219 professores de 75 escolas da rede estadual de ensino de Minas Gerais.

\section{Resultados e discussões}

O NTE no qual foi realizado a entrevista é responsável pelo atendimento de 75 escolas estaduais, das quais somente uma não possui laboratório de informática. $\mathrm{O}$ gestor pedagógico relata que as ferramentas tecnológicas em grande parte das escolas passaram por manutenção recente e em algumas escolas estão sendo finalizadas as reformas nos laboratórios de informática. Se referindo às propostas de formação continuada realizadas, são levantadas implicações e desafios: o NTE não possui autonomia para convocar professores para as capacitações, geralmente apresenta-se propostas para as escolas, ou a equipe gestora propõe propostas de formação ao NTE, que realiza as capacitações na mesma escola ou na Superintendência Regional de Ensino à qual pertence.

Outro desafio encontrado é o tempo do professor para formação, visto que alguns trabalham os três turnos, nesse caso existem impasses de ordem administrativa, visto que os professores teriam que se ausentar da sala de aula para a formação. São realizadas alternativas para auxiliar o professor, assim como visita as escolas e capacitação de professores no horário de coordenação/planejamento pedagógico, porém dessa forma haverá um longo período para atender a maior parte dos docentes, visto que o recurso humano do NTE é pequeno em razão do número de escolas que atende.

\subsection{Perfil dos docentes}

Com relação ao perfil dos docentes que responderam ao questionário, verificou-se que são de diferentes disciplinas do ensino: Pedagogia, Português, Matemática, Ciências, Educação Física, Geografia, História, Inglês, Química, Física, Filosofia, Sociologia e outras. Ao que se refere a formação desses profissionais $97,3 \%$ possuem licenciatura, obtendo uma porcentagem mínima de $2,7 \%$ de professores sem licenciatura (Figura 1). 
V Congresso Brasileiro de Informática na Educação (CBIE 2016)

Anais do XXII Workshop de Informática na Escola (WIE 2016)

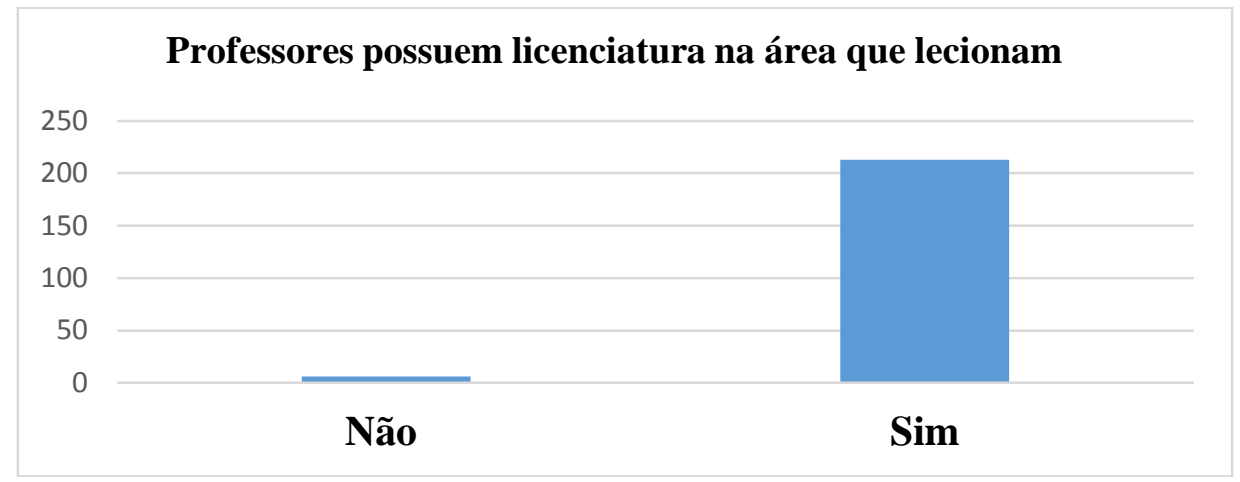

Figura 1. Professores possuem licenciatura na área que lecionam

Quanto ao gênero, tem-se uma quantidade considerável do sexo feminino $(81,7 \%)$ obtendo somente $18,3 \%$ do sexo masculino. Sendo que, a maioria dos professores lecionam no ensino fundamental II $(39,7 \%)$, seguido pelo ensino fundamental I $(27,9 \%)$ e ensino médio $(31,5 \%)$, tendo uma parcela mínima que leciona no ensino técnico $(0,9 \%)$. Cerca de $94 \%$ dos professores tem acesso a algum tipo de recurso tecnológico na escola, sendo o retroprojetor e o laboratório de informática os mais comuns (Figura 2). Sabe-se, que as ferramentas contribuem para a execução das atividades propostas, no entanto fazse necessário planejar a integração da tecnologia na cultura da escola.

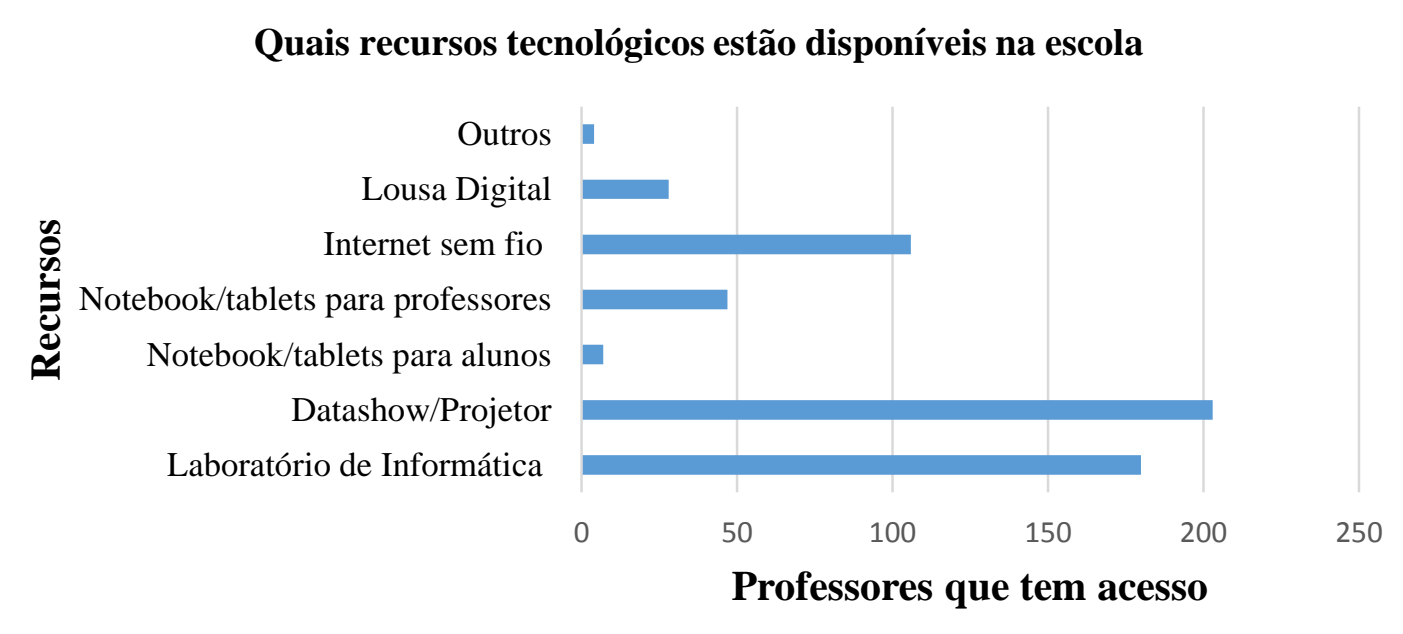

Figura 2. Quais recursos estão disponíveis na escola.

Ao final da pesquisa, o professor foi questionado, o motivo pelo qual alguns professores são resistentes em incorporar em suas aulas as novas tecnologias 33,8\% acreditam que a resistência é devido à falta de formação continuada, que permita a renovação do conhecimento (Figura 3). Em 2004, a Secretaria Estadual de Educação de Minas Gerais (SEEMG) lançou o "Projeto Escolas em Rede" planejado para 5 anos de execução, que também tinha proposta de capacitação de professores na temática das novas tecnologias, porém a formação era ofertada diretamente para alguns professores da rede, e a proposta contemplava mais à informática instrumental, ou seja, a competência de aprender sobre o software, do que usá-lo com objetivos pedagógicos. Além, de passar por desafios como a falta de comprometimento do MEC no cumprimento do prazo de entrega dos equipamentos na escola. 


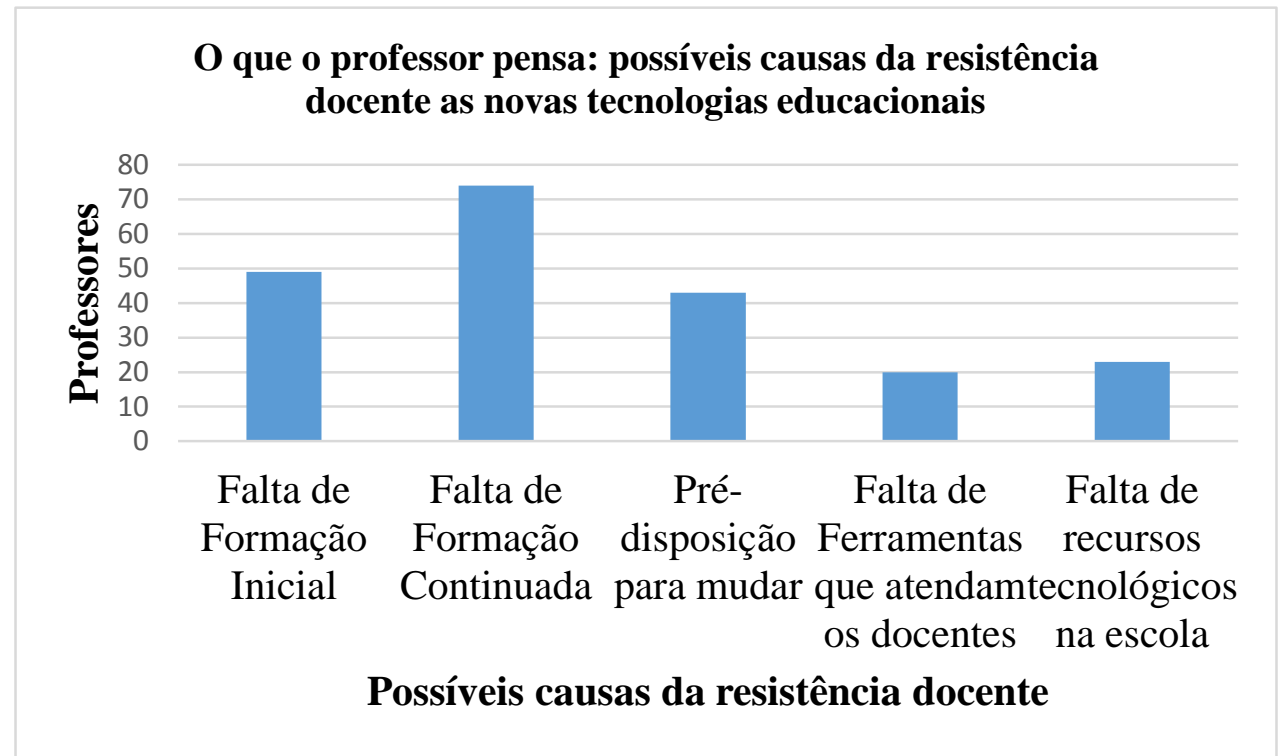

Figura 3. O que o professor pensa: possíveis causas da resistência docente as novas tecnologias educacionais.

A opinião do professor é construída dentro de sua profissão, ele percebe a necessidade de uma formação que seja contínua e que colabore para a mudança de suas práticas, por outro lado também observa-se que tem professores que não possuem uma pré-disposição para a mudança de suas práticas. Porém, é necessário que o professor conceba a formação como uma nova forma de (re)pensar seu trabalho (Dias e Lopes, 2003). Assim, para Freire (2001) o professor tem o dever de se capacitar antes de iniciar sua atividade docente e fazer da formação um processo permanente, pois como ensinante ele possui responsabilidade ética, política e profissional. Porém, em estudo feito pelo Instituto Ayrton Senna (IAS) em parceria com The Boston Consulting Group (BCG) os professores brasileiros que arcam com os custos de formação continuada possuem menos tempo reservado para a capacitação, além de receber menos incentivos do que em outros países.

\section{Considerações finais}

O artigo buscou analisar a seguinte indagação: a visão do gestor frente as políticas de formação continuada envolvendo as novas tecnologias reflete a realidade do professor? Por meio da entrevista ao NTE, que é responsável por apoiar o processo de planejamento e gestão de uso das tecnologias nas escolas e a análise do questionário enviado aos professores, percebe-se que a gestão é ciente das propostas de políticas de formação continuada, no entanto nem sempre é possível executá-las com perfeição visto aos diversos fatores envolvidos, dentre eles a quantidade de recursos humanos no NTE para atender diversas escolas, a demanda interna da escola e a sobrecarga de trabalho do professor. Por outro lado, observa-se que há uma parcela dos professores que buscam formação externa, esses podem não ter ciência das ações do NTE em parceria com a escola.

Portanto, faz-se necessário o diálogo entre os professores e a equipe diretiva da escola, para a construção de projetos que em parceria com o NTE regional possam ser meios de formação continuada dos docentes, visto que o diálogo permite perceber e 
V Congresso Brasileiro de Informática na Educação (CBIE 2016)

Anais do XXII Workshop de Informática na Escola (WIE 2016)

analisar por diferentes a proposta da gestão atrelada a realidade dos professores. Não foi o foco do artigo, mas as análises mostram que é necessário alinhar políticas públicas permanentes que garantam o direito do professor a formação continuada de forma efetiva. Para trabalhos futuros, pretende-se realizar a análise em documentos emitidos pelo Ministério da Educação-MEC que são referentes a formação continuada de professores no Brasil.

\section{Referências}

Almeida, M.; Menezes, L.C.B.R. (2004). "O papel do gestor escolar na incorporação das TIC na escola: experiências em construção e redes colaborativas de aprendizagem”. São Paulo, PUC-SP.

Brasil. Ministério da Educação, Gabinete de Informação e Avaliação do Sistema Educativo. Disponível em: $<$ http://www.giase.minedu.pt/nonio/docum/document.htm>. Acesso em: Jun. 2016.

Brito, C.; Duarte, J. e Baía, M. (2004) "As tecnologias de informação na formação contínua de professores: uma nova leitura da realidade".

Dias, R. E.; Lopes, A. C. (2003) "Competências na formação de professores no Brasil: o que (não) há de novo”. Educação \& Sociedade, v. 24, n. 85, p. 1155-1177.

Fernandes, R. C. M. (2006) "Atitudes dos Professores Face às TIC e a sua utilização ao nível do ensino secundário”. Lisboa, 2006. Dissertação (Mestrado em Educação)Faculdade de Psicologia e Ciências da Educação, Universidade de Lisboa.

Figueiredo, G. L. R.; Nobre, I. A. M.; Passos, M. L. S.; (2015) "Tecnologias Computacionais na Educação: Desafios na Prática Docente”. In: CBIE-LACLO 2015; Anais do XXI Workshop de Informática na Escola (WIE 2015).

Freire, P. (2001) “Carta de Paulo Freire aos professores”. Estudos avançados, v. 15, n. 42, p. 259-268.

IAS. Instituto Ayrton Senna.(2016) "Formação continuada de professores do Brasil". Disponível em: < http://educacaosec21.org.br/formacaocontinuada/> Acesso em Jun. 2016

Inep. (2007) "Estudo exploratório sobre o professor brasileiro com base nos resultados do Censo Escolar da Educação Básica 2007”. Disponível em: < http://portal.mec.gov.br/dmdocuments/estudoprofessor.pdf $>$. Acesso em: 09 Fev. 2016.

Lisbôa, E. et al. (2009) "LMS em contexto escolar: estudo sobre o uso da Moodle pelos docentes de duas escolas do concelho de Braga". Educação, Formação \& Tecnologias, v. 2, n. 1, p. 44-57.

Martia, E. EAD: mudança de paradigmas pedagógicos. Disponível em: < http://www.administradores.com.br/artigos/carreira/ead-mudanca-de-paradigmaspedagogicos/23386/> Acesso em Ago. 2016

Perrenoud, P. (2000) "Dez novas competências para ensinar". Artmed editora.

Real, L. C.; Tavares, M. R. N. (2015) "Tablets educacionais: formação de professores e mudanças na aprendizagem". In: Anais dos Workshop do Congresso Brasileiro de Informática na Educação (CBIE 2015). 